\title{
Analisis Penerapan Sistem Manajemen K3 dan Kelengkapan Fasilitas K3 Pada Proyek Konstruksi Gedung Di Surabaya
}

\author{
Arizal Firmansyah Priyono ${ }^{1}$ dan Feri Harianto ${ }^{2}$ \\ ${ }^{1,2}$ Jurusan Teknik Sipil, Fakultas Teknik Sipil dan Perencanaan,ITATS, Surabaya \\ E-mail: arizal.firmans@gmail.com ${ }^{1}$,gokbio@yahoo.com ${ }^{2}$
}

\begin{abstract}
ABSTRAK:Proyek konstruksi gedung bertingkat memiliki risiko kecelakaan kerja yang tinggi, khususnya bagi pekerja di lapangan. Oleh karena itu, perlu adanya penerapan Sistem Manajemen K3 serta fasilitas K3 yang lengkap dan layak di lokasi kerja. Sistem Manajemen K3 merupakan bagian dari perencanaan dan pengendalian kecelakaan pada proyek konstruksi. Tujuan penelitian ini adalah menganalisis penerapan SMK3 dan kelengkapan fasilitas K3 serta membandingkan antara 3 proyek konstruksi gedung yang ada di Kota Surabaya. Metode penelitian yang digunakan adalah metode survai dengan pengambilan data dilakukan melalui kuesioner dengan respondennya adalah Manager, Safety Officer dan Quality Control. Analisis penerapan Sistem Mnajemen K3 berdasarkan audit Permenaker no.5 tahun 1996. Hasil dari penelitian ini untuk proyek Apartemen BeSS Mansion nilai rata-rata pencapaian adalah 92,56\% , proyek Gedung Ciputra World nilai rata-rata pencapaian 91,80\% , dan proyek Gedung C dan Masjid Kampus Perbanas II nilai rata-rata pencapaian $89,76 \%$. Kriteria ketiga proyek tersebut adalah memuaskan. Sedangkan hasil analisis kelengkapan APD dan fasilitas K3 pada proyek Apartemen BeSS Mansion mendapat nilai rata-rata 95,55\%, proyek Gedung Ciputra World dengan nilai rata-rata 93,67\%, dan pada proyek Gedung C dan Masjid Kampus Perbanas II mendapat nilai rata-rata 73,33\%. Adapun terdapat 4 faktor yang mempengaruhi perbedaan dalam penerapan SMK3 di ketiga proyek tersebut yaitu faktor perencanaan, faktor perusahaan kontraktor, faktor kesiapan manajemen, faktor kesadaran manajemen. Dengan demikian, untuk ketiga proyek tersebut telah siap Permenaker no.5 tahun 1996. Namun perlu adanya perbaikan atau perencanaan kembali pada kriteria-kriteria yang tidak sesuai, serta memperhatikan APD dan fasilitas proyek yang kurang layak dan tidak lengkap.
\end{abstract}

Kata Kunci : keselamatan, kesehatan, manajemen k3, fasilitas k3, perbandingan

\section{PENDAHULUAN}

Pembangunan yang dilakukan dengan teknologi sederhana maupun tinggi tidak pernah luput dari adanya resiko kecelakaan kerja. Pada tahun 2017 angka kecelakaan kerja mengalami penurunan dibandingkan tahun 2016, tercatat terjadi sebanyak 80.393 kasus kecelakaan kerja di Indonesia. Selain itu perusahaan yang menerapkan Sistem Manajemen K3 meningkat 69,1\% dibandingkan tahun 2016, yakni diangka 1.221 perusahaan (Kementerian Ketenagakerjaan, 2018).

Keselamatan kerja mengandung arti cara seseorang untuk menjaga diri atau orang lain karena beban kerja yang ada di lapangan mengharuskan seorang pekerja mendapat perlindungan tersebut agar mereka dapat bekerja secara maksimal. Untuk mengurangi kecelakaan kerja maka perusahaan wajib menerapkan sistem keselamatan kerja yang baik dan tegas. Maka perlu diterapkan Sistem Manajemen Keselamatan dan Kesehatan Kerja (SMK3) di dalam sebuah proyek untuk meningkatkan perlindungan kepada pekerja (PP nomor 50 tahun 2012).

Keselamatan dan kesehatan kerja (K3) merupakan suatu pemikiran dan upaya untuk menjamin keutuhan dan kesempurnaan baik jasmani maupun rohani tenaga kerja pada khususnya, dan manusia pada umumnya, hasil karya dan budaya untuk menuju masyarakat adil dan makmur (Mangkunegara, 2002).

Keselamatan kerja merupakan rangkaian usaha untuk mewujudkan suasana kerja yang aman dan tentram bagi para karyawan atau pekerja yang bekerja pada perusahaan yang bersangkutan (Suma'mur, 2001).

Pelaksanaan keselamatan dan kesehatan kerja yang baik diperlukan untuk meminimalkan kecelakaan dalam bekerja khususnya pada proyek konstruksi. Oleh karena itu perlu adanya penelitian tentang tingkat pelaksanaan keselamatan dan kesehatan kerja dan fasilitas-fasilitas keselamatan kerja di proyek konstruksi agar kedepannya dapat dilakukan tindakan-tindakan untuk mengurangi kecelakaan kerja pada proyek konstruksi.

\section{METODE PENELITIAN}

Metode yang digunakan adalah metode survai, dengan pengumpulan melalui kuesioner. Teknik pengambilan sampel menggunakan metode NonProbability Sampling dengan teknik Purposive Sampling, yakni sampel atau responden yang dipilih berdasarkan kriteria jabatan dan pemahaman materi K3 di lapangan.

Lokasi penelitian dilakukan di 3 proyek konstruksi gedung yang berbeda di Kota Surabaya,

1. Proyek Pembangunan Apartement BeSS Mansion,

Kota Surabaya. Terletak di Jalan Raya Jemursari no.15, Surabaya.

2. Proyek Pembangunan Gedung Ciputra World, Kota Surabaya. Terletak di Jalan Raya Mayjend

Sungkono, Surabaya

3. Proyek Pembangunan Gedung C dan Masjid

Kampus 2 STIE Perbanas, Kota Surabaya. Terletak

di Jalan Wonorejo Utara no.16, Surabaya.

Penelitian ini menggunakan 2 tahapan kuesioner yang ditujukan kepada responden adalah sebagai berikut:

a) Kuesioner jenis check list dengan metode skala Guttman, yaitu kuesioner jenis check-list yang menggunakan jawaban bersifat jelas, tegas, dan konsisten, seperti: ya - tidak, sesuai - tidak sesuai, benar - salah, positif - negatif, dan lain sebagainya (Riduwan, 2003). Kuesioner berisi 166 poin pertanyaan mengenai Sistem Manajemen K3 mengacu pada Pedoman Daftar 
Periksa Audit Penilaian Penerapan Sistem Manajemen K3 Permenaker nomor 5 tahun 1996 dengan jawaban "sesuai" dan "tidak sesuai". Kriteria pencapian penerapan seperti pada tabel 1.

Tabel 1. Tingkat Pencapaian Penerapan SMK3

\begin{tabular}{cc}
\hline \multicolumn{2}{c}{ Tingkat Pencapaian Penerapan } \\
\hline $0-59 \%$ & Kurang \\
$60-84 \%$ & Baik \\
$85-100 \%$ & Memuaskan \\
\hline Sumber:Permenaker
\end{tabular}

Sumber : Permenaker no.5 thn 1996

b) Kuesioner penelitian kelengkapan fasilitas Keselamatan dan Kesehatan Kerja dengan menggunakan metode skala likert, yaitu kuesioner yang menggunakan pengukuran sikap, pendapat dan persepsi dari responden tentang suatu kejadian yang variabelnya telah ditetapkan secara spesifik oleh peneliti (Riduwan, 2003). Adapun skala pengukurannya yaitu :

$1=$ Jika tidak tersedia,

2 = jika tersedia, tidak layak, dan tidak lengkap

$3=$ jika tersedia, layak, dan tidak lengkap

$4=$ jika tersedia, tidak layak, dan lengkap

$5=$ jika tersedia, layak, dan lengkap

Dari kedua analisis tersebut diperoleh hubungan antara penerapan sistem manajemen K3 dengan kelengkapan fasilitas K3 yang digunakan pada saat pelaksanaan kegiatan proyek. Karena kedua hal tersebut saling mempengaruhi, misalnya saja fasilitas K3 yang digunakan tidak lengkap atau pun tidak layak, maka dapat mempengaruhi nilai dari penerapan sistem manajemen K3 pada proyek tersebut

\section{HASIL DAN PEMBAHASAN \\ Profil Responden}

Data responden yang diambil adalah nama responden, nama instansi, pendidikan terakhir, jabatan dalam pekerjaan, dan lama bekerja. Responden didominasi lulusan Strata 1 (S1) dengan lama bekerja antara 1-5 tahun. Penjabaran dapat dilihat pada Gambar1,2, dan 3 :

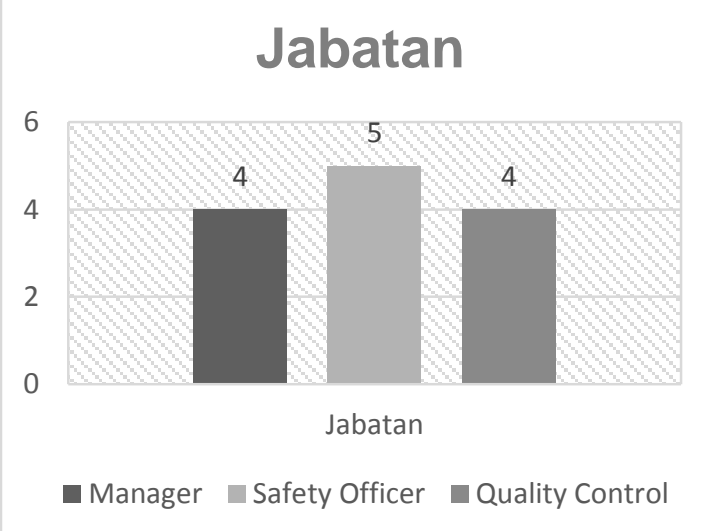

Gambar 1 Jabatan Responden Sumber : Hasil Olahan

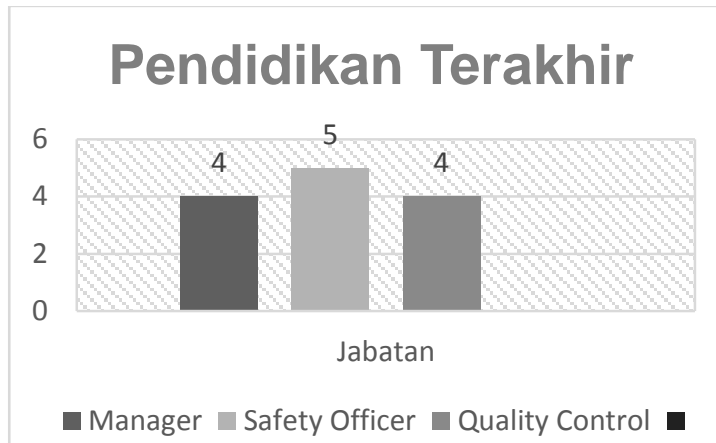

Gambar 2 Pendidikan Responden

Sumber : Hasil Olahan

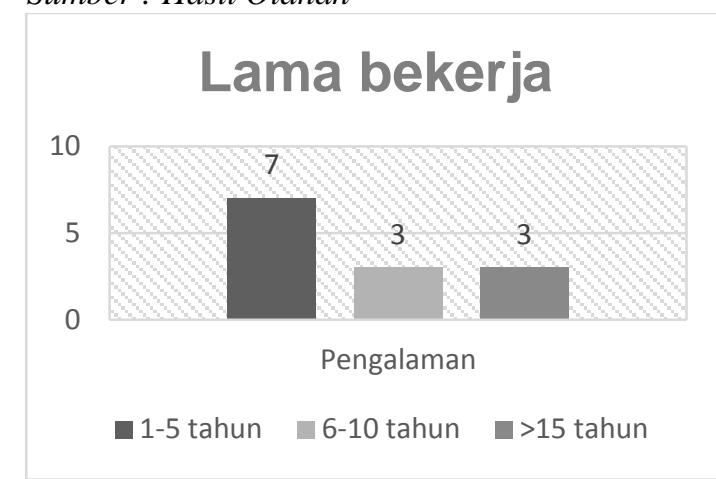

Gambar 3 Lama Bekerja Responden

Sumber : Hasil Olahan

\section{Penerapan Sistem Manajemen K3}

Penerapan SMK3 di audit berdasarkan Permenaker no.5 tahun 1996. Perhitungan check list ini menggunakan rumus :

$\frac{\sum \text { Nilai Pemenuhan }}{166 \text { kriteria }}$ X 100\% $=$ Persentase Pencapaian

1. Proyek Apartemen BeSS Mansion

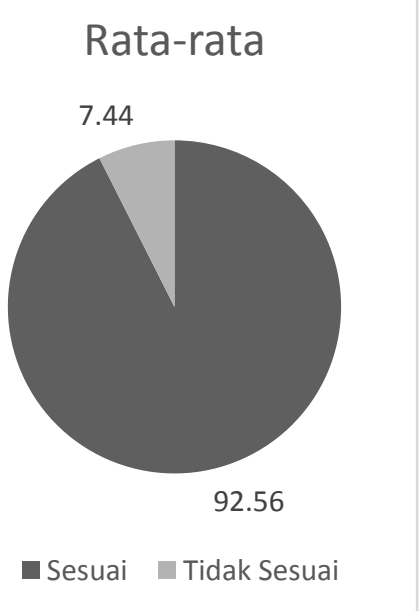

Gambar 4 Mean Pencapaian Penerapan SMK3 di Proyek BeSS Mansion Sumber : Hasil Olahan

Pada proyek Apartemen BeSS Mansion didapat nilai rata-rata memuaskan yaitu 92,56\%, namun ada beberapa kertidaksesuaian yang berpotensi dapat berdampak kurang baik bagi jalannya proyek. Adapun beberapa kriteria yang tidak sesuai dengan 
Permenaker no.5 tahun 1996 yang sama dari ketiga responden tersebut.

- Tentang Manual SMK3 :

- Manual SMK3 meliputi kebijakan, tujuan, rencana, prosedur SMK3, instruksi kerja, formulir, catatan dan tanggung jawab serta wewenang tanggung jawab K3 untuk semua tingkatan dalam perusahaan

- Terdapat manual khusus yang berkaitan dengan produk, proses, atau tempat kerja tertentu

- Manual K3 mudah didapat oleh semua personil dalam perusahaan sesuai kebutuhan

2. Proyek Gedung Ciputra World

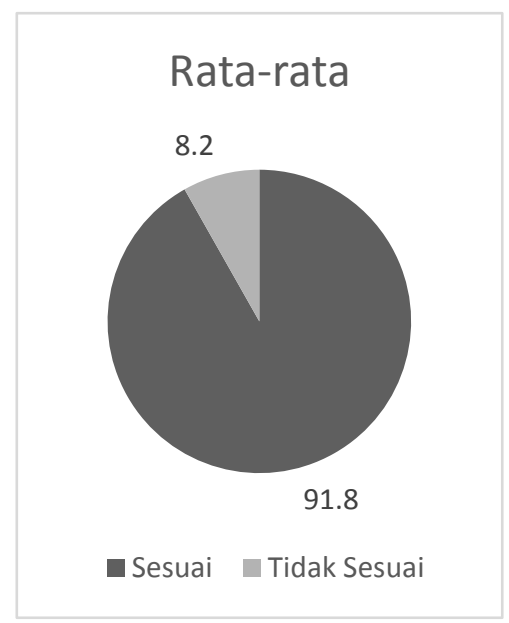

Gambar 5 Mean Pencapaian Penerapan SMK3 di Proyek Ciputra World

Sumber : Hasil Olahan

Pada proyek Gedung Ciputra World didapat nilai rata-rata memuaskan yaitu $91,80 \%$, namun ada beberapa kertidaksesuaian yang berpotensi dapat berdampak kurang baik bagi jalannya proyek. Adapun beberapa kriteria yang tidak sesuai dengan Permenaker no.5 tahun 1996 yang sama dari kelima responden tersebut.

- Perubahan dan Modifikasi Dokumen

- Terdapat sistem untuk membuat, menyetujui perubahan terhadap dokumen K3

- Pemeriksaan Bahaya

- Alat dipelihara dan dikalibrasi oleh petugas atau pihak yang berkompeten dan berwenang dari dalam dan/atau luar perusahaan

- Sistem Pengangkutan, Penyimpanan dan Pembuangan

- Terdapat prosedur yang menjamin bahwa bahan dibuang dengan cara yang aman dan sesuai dengan peraturan perundang-undangan

- Pengendalian Bahan Kimia Berbahaya (BKB)

- Perusahaan telah mendokumentasikan dan menerapkan prosedur mengenai penyimpanan, penanganan, dan pemindahan BKB sesuai dengan peraturan peundang-undangan, tandar dan pedoman teknis yang relevan

- Terdapat lembar data keselamatan BKB meliputi keterangan mengenai keselamatan bahan sebagaimana diatur pada peraturan perundang-undangan dan dengan mudah dapat diperoleh

- Pengembangan Keterampilan dan Kemampuan

- Jenis pelatihan K3 yang dilakukan harus disesuaikan dengan kebutuhan untuk pengendalian potensi bahaya

- Pelatihan dilakukan oleh orang atau badan yang berkompeten dan berwenang sesuai peruindang-undangan

- Terdapat fasilitas dan sumber daya memadai untuk pelaksanaan pelatihan yang efektif

- Pengusaha atau pengurus mendokumentasikan dan menyimpan seluruh catatan pelatihan

- Anggota manajemen eksekutif dan pengurus berperan serta dalam pelatihan yang mencakup penjelasan tentang kewajiban hokum dan prinsip-prinsip serta pelaksanaan K3

- Pelatihan diberikan kepada tenaga kerja apabila di tempat kerja terjadi perubahan sarana produksi atau proses

- Pengusaha atau pengurus memberikan pelatihan penyegaran kepada semua tenaga kerja

- Terdapat prosedur yang menetapkan persyaratan untuk memberikan briefing kepada pengunjung dan mitra kerja guna menjamin K3

- Perusahaan mempunyai sistem yang menjamin kepatuhan terhadap persyaratan lisensi atau kualifikasi sesuai dengan perundang-undangan untuk melaksanakan tugas khusus, melaksanakan pekerjaan atau mengoperasikan peralatan

3. Proyek Gedung C dan Masjid Kampus Perbanas II

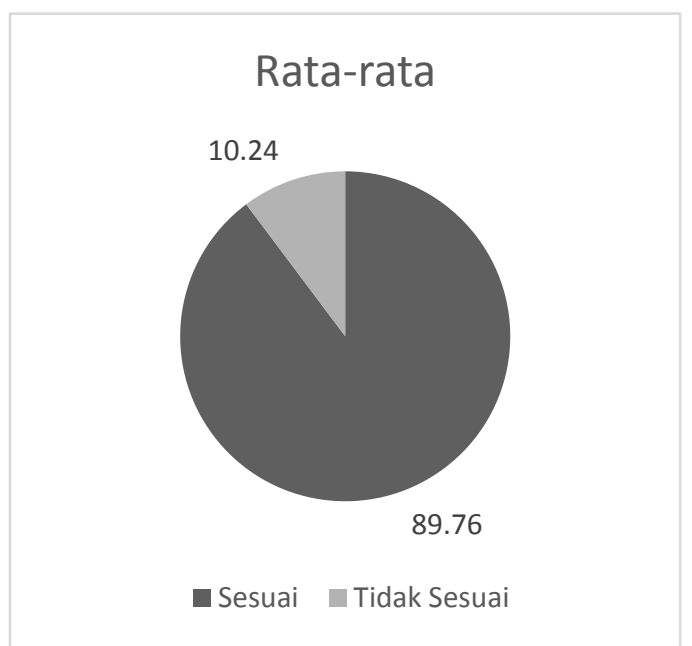

Gambar 6 Mean Pencapaian Penerapan SMK3 di Proyek Kampus Perbanas II

Sumber : Hasil Olahan

Pada proyek Kampus Perbanas didapat nilai ratarata memuaskan yaitu $89,76 \%$, namun ada beberapa kertidaksesuaian yang berpotensi dapat berdampak kurang baik bagi jalannya proyek. Adapun beberapa kriteria yang tidak sesuai dengan 
Permenaker no.5 tahun 1996 yang sama dari kelima responden tersebut.

- Kemampuan Telusur Produk

- Semua produk yang digunakan dalam proses produksi dapat diidentifikasi diseluruh tahapan produksi dan instalasi, jika terdapat potensi masalah K3

- Terdapat prosedur yang terdokumentasi untuk penelusuran produk yang telah terjual, jika terdapat potensi masalah $\mathrm{K} 3$ didalam penggunaannya

- Pengendalian Bahan Kimia Berbahaya (BKB)

- Perusahaan telah mendokumentasikan dan menerapkan prosedur mengenai penyimpanan, penanganan, dan pemindahan BKB sesuai dengan peraturan peundang-undangan, tandar dan pedoman teknis yang relevan

- Terdapat lembar data keselamatan BKB meliputi keterangan mengenai keselamatan bahan sebagaimana diatur pada peraturan perundang-undangan dan dengan mudah dapat diperoleh

- Terdapat sistem untuk mengidentifikasi dan pemberian label secara jelas pada BKB

- Rambu peringatan bahaya terpasang sesuai dengan persyaratan perundangan

- Penanganan BKB dilakukan oleh pihak yang berkompeten atau berwenang

- Catatan K3

- Terdapat prosedur yang menentukan persyaratan untuk menjaga kerahasiaan catatan

- Catatan kompensasi kecelakaan dan rehabilitasi kesehatan tenaga kerja dipelihara

\section{Kelengkapan Alat Pelindung Diri dan Fasilitas K3}

Penilaian terhadap Alat Pengaman Diri dan Fasilitas K3 dalam 3 studi kasus mendapatkan hasil yang bervariasi dari masing-masing responden pada setiap proyek. Hal ini karena kebijakan, dan faktor-faktor lain yang mempengaruhi dari proyek yang diteliti. Perhitungan persentase dapat dihitung dengan rumus :

$\frac{\text { total skor yang didapat }}{\sum \text { skor maksimal }}$
kelengkapan

Tabel 2 Persentase Kelengkapan Fasilitas K3

\begin{tabular}{lc}
\hline Nama Proyek & $\begin{array}{l}\text { Kelengkapan } \\
\text { Fasilitas K3 (\%) }\end{array}$ \\
\hline Apartemen BeSS Mansion & 95,55 \\
Gedung Ciputra World & 93,67 \\
Gedung C dan Masjid Perbanas & 73,33 \\
II & \\
\hline
\end{tabular}

Sumber: Hasil Olahan

\section{Hubungan Penerapan SMK3 dengan Kelengkapan Fasilitas K3}

Dari hasil analisis data kuesioner penerapan sistem manajemen K3 dan kelengkapan fasilitas K3 dapat direkap persentase angka rata-rata di ketiga proyek yang dapat dilihat pada tabel 3 .
Tabel 3 Rekapitulasi Persentase Kuesioner

$\begin{array}{lll} & \text { Penerapan } & \text { Kelengkapan } \\ \text { Nama Proyek } & \text { SMK3 (\%) } & \text { Fasilitas K }\end{array}$
(\%)

\begin{tabular}{lcc} 
Apartemen BeSS & 92,56 & 95,55 \\
$\begin{array}{l}\text { Mansion } \\
\text { Gedung Ciputra World }\end{array}$ & 91,80 & 93,67 \\
$\begin{array}{l}\text { Gedung C dan Masjid } \\
\text { Perbanas II }\end{array}$ & 89,76 & 73,33 \\
\hline
\end{tabular}

Sumber : Hasil Olahan

Berdasarkan tabel 3 kelengkapan fasilitas K3 mempengaruhi besarnya nilai penerapan K3 di proyek, hal tersebut dapat dikarenakan pentingnya alat pelindung diri maupun fasilitas pengaman proyek guna menunjang keselamatan pekerja di lapangan disamping dengan baiknya manajemen K3 yang direncanakan dan diimplementasikan di proyek konstruksi gedung.

\section{Perbandingan Penerapan Sistem Manajemen K3 dan Kelengkapan Fasilitas K3 di ketiga proyek}

Pada tabel 2 dapat dilihat bahwa adanya perbedaan persentase di ketiga proyek, jika ditinjau lebih detail, pada analisis data kuesioner ada perbedaan pada poin-poin penerapan SMK3 yang tidak sesuai dengan Permenaker no.5 tahun 1996, dan juga pada kelengkapan fasilitas K3 di masing-masing proyek. Perbandingan ketidaksesuaian penerapan K3 dapat dilihat di tabel 4.

Tabel 4 Ketidaksesuaian Penerapan SMK3

\begin{tabular}{|c|c|c|c|}
\hline Kriteria & $\begin{array}{c}\text { Apartement } \\
\text { BeSS } \\
\text { Mansion } \\
\text { (A) }\end{array}$ & $\begin{array}{c}\text { Gedung } \\
\text { Ciputra } \\
\text { World } \\
\text { (B) }\end{array}$ & $\begin{array}{c}\text { Gedung } \\
\text { C dan } \\
\text { Masjid } \\
\text { Perbanas } \\
\text { II }(\text { C })\end{array}$ \\
\hline Manual SMK3 & $\begin{array}{l}\text { Tidak } \\
\text { Sesuai }\end{array}$ & $\sqrt{ }$ & $\sqrt{ }$ \\
\hline $\begin{array}{l}\text { Perubahan dan } \\
\text { Modifikasi } \\
\text { Dokumen }\end{array}$ & $\sqrt{ }$ & $\begin{array}{c}\text { Tidak } \\
\text { Sesuai }\end{array}$ & $\sqrt{ }$ \\
\hline $\begin{array}{l}\text { Kemampuan } \\
\text { Telusur Produk }\end{array}$ & $\sqrt{ }$ & $\sqrt{ }$ & $\begin{array}{l}\text { Tidak } \\
\text { Sesuai }\end{array}$ \\
\hline $\begin{array}{l}\text { Sistem } \\
\text { Pengangkutan, } \\
\text { Penyimpanan, } \\
\text { dan } \\
\text { Pembuangan }\end{array}$ & $\sqrt{ }$ & $\begin{array}{l}\text { Tidak } \\
\text { Sesuai }\end{array}$ & $\sqrt{ }$ \\
\hline Catatan K3 & $\sqrt{ }$ & $\sqrt{ }$ & $\begin{array}{l}\text { Tidak } \\
\text { Sesuai }\end{array}$ \\
\hline $\begin{array}{l}\text { Pengendalian } \\
\text { BKB }\end{array}$ & $\sqrt{ }$ & $\begin{array}{l}\text { Tidak } \\
\text { Sesuai }\end{array}$ & $\begin{array}{l}\text { Tidak } \\
\text { Sesuai }\end{array}$ \\
\hline $\begin{array}{l}\text { Pengembangan } \\
\text { Keterampilan } \\
\text { dan } \\
\text { Kemampuan }\end{array}$ & $\sqrt{ }$ & $\begin{array}{l}\text { Tidak } \\
\text { Sesuai }\end{array}$ & $\sqrt{ }$ \\
\hline
\end{tabular}

Sumber : Hasil Olahan 
Berdasarkan Tabel 4, dapat diambil beberapa faktor yang menjadikan kriteria yang tidak sesuai dan mempengaruhi perbedaan yang terjadi di lapangan.

1. Faktor Perencanaan SMK3

Perencanaan manajemen K3 merupakan awal dari berjalannya sistem K3 di lapangan, dengan adanya manajemen yang baik perlu diikuti juga dengan implementasi rencana $\mathrm{K} 3$ demi menjamin keselamatan pekerja di lapangan

\section{Faktor Perusahaan Kontraktor}

Badan usaha kontraktor yang menjalankan proyek juga berpengaruh terhadap penerapan SMK3 maupun kelengkapan fasilitas yang dimiliki. Proyek A dijalankan oleh kontraktor BUMN atau milik pemerintah, sedangkan proyek $\mathrm{B}$ dan $\mathrm{C}$ merupakan perusahaan milik swasta kelas tinggi dan menengah. Meski begitu penerapan SMK3 dan kelengkapan fasilitas K3 yang dimiliki perusahaan swasta ini cukup memuaskan, namun perlu sedikit pembenahan agar tetap menjamin keselamatan pekerja di lapangan

Tabel 5 Perbandingan Ketidaksesuaian APD dan Fasilitas K3

\begin{tabular}{|c|c|c|c|}
\hline $\begin{array}{c}\text { APD dan } \\
\text { Fasilitas } \mathrm{K} 3 \\
\text { tidak sesuai }\end{array}$ & $\begin{array}{c}\text { Apartem } \\
\text { ent BeSS } \\
\text { Mansion } \\
(A)\end{array}$ & $\begin{array}{c}\text { Gedung } \\
\text { Ciputra } \\
\text { World }(B)\end{array}$ & $\begin{array}{c}\text { Gedung C } \\
\text { dan } \\
\text { Masjid } \\
\text { Perbanas } \\
\text { II }(C) \\
\end{array}$ \\
\hline Gloves & $\sqrt{ }$ & $\sqrt{ }$ & $\begin{array}{c}\text { Tidak } \\
\text { Lengkap }\end{array}$ \\
\hline Rompi & $\sqrt{ }$ & $\begin{array}{l}\text { Tidak } \\
\text { Layak }\end{array}$ & $\begin{array}{c}\text { Tidak } \\
\text { Lengkap }\end{array}$ \\
\hline Masker & $\sqrt{ }$ & $\begin{array}{l}\text { Tidak } \\
\text { Layak }\end{array}$ & $\begin{array}{c}\text { Tidak } \\
\text { Lengkap }\end{array}$ \\
\hline Body Harness & $\sqrt{ }$ & $\begin{array}{c}\text { Tidak } \\
\text { Lengkap }\end{array}$ & $\sqrt{ }$ \\
\hline $\begin{array}{l}\text { Rambu- } \\
\text { rambu }\end{array}$ & $\sqrt{ }$ & $\sqrt{ }$ & $\begin{array}{c}\text { Tidak } \\
\text { Lengkap }\end{array}$ \\
\hline Spanduk K3 & $\sqrt{ }$ & $\sqrt{ }$ & $\begin{array}{c}\text { Tidak } \\
\text { Lengkap }\end{array}$ \\
\hline $\begin{array}{l}\text { Alarm } \\
\text { Peringatan }\end{array}$ & $\sqrt{ }$ & $\begin{array}{l}\text { Tidak } \\
\text { Layak }\end{array}$ & Tidak Ada \\
\hline $\begin{array}{l}\text { Lampu } \\
\text { Peringatan }\end{array}$ & $\begin{array}{l}\text { Tidak } \\
\text { Layak }\end{array}$ & $\sqrt{ }$ & $\begin{array}{c}\text { Tidak } \\
\text { Lengkap }\end{array}$ \\
\hline
\end{tabular}

Sumber : Hasil Olahan

Berdasarkan Tabel 5, dapat diambil beberapa faktor yang menjadikan fasilitas K3 dan APD yang kurang lengkap dan layak, dan dapat mempengaruhi perbedaan yang terjadi di lapangan.

1. Faktor Kesiapan Manajemen

Kesiapan dari manajemen yang dimaksudkan adalah memfasilitasi pekerja dengan Alat Pelindung Diri (APD) yang layak dan juga lengkap, serta mengecek fasilitas pengaman proyek yang mereka miliki apakah berfungsi dengan baik atau tidak

2. Faktor Kesadaran Manajemen

Kesadaran yang dimaksud adalah pihak manajemen sadar akan keselamatan para pekerja, sehingga mereka perlu memperhatikan alat-alat pelindung diri pekerja apakah sudah layak, dan fasilitas K3 yang ada di proyek seperti spanduk, rambu, alarm, dan lain sebagainya apakah sudah lengkap dang berfungsi sebagaimana mestinya

\section{UCAPAN TERIMAKASIH}

Terima kasih atas kerjasamanya dalam penelitian kepada pihak manajemen PT Adhi Persada Gedung, PT Tatamulia Nusantara Indah, dan PT Tajimaka

\section{KESIMPULAN DAN SARAN \\ Kesimpulan}

Penelitian ini dapat disimpulkan sebagai berikut :

1. Di proyek konstruksi gedung yang diteliti sudah menerapkan Sistem Manajemen K3 dengan baik, tetapi belum $100 \%$. Berdasarkan Permenaker no.5 tahun 1996, untuk proyek Apartemen BeSS Mansion nilai rata-rata pencapaian adalah $92,56 \%$ dengan nilai memuaskan, proyek Gedung Ciputra World nilai rata-rata pencapaian $91,80 \%$ dengan nilai memuaskan, dan proyek Gedung $\mathrm{C}$ dan Masjid Kampus Perbanas II nilai rata-rata pencapaian $89,76 \%$ dengan nilai memuaskan.

2. Nilai kelengkapan Alat Pelindung Diri (APD) dan failitas K3 pada 3 proyek yang diteliti menunjukkan angka persentase yang cukup baik, pada proyek Apartemen BeSS Mansion mendapat nilai rata-rata $95,55 \%$, proyek Gedung Ciputra World dengan nilai rata-rata 93,67\%, dan pada proyek Gedung $\mathrm{C}$ dan Masjid Kampus Perbanas II mendapat nilai rata-rata $73,33 \%$.

3. Perbandingan antara ketiga proyek menunjukkan bahwa perbedaan tersebut dipengaruhi oleh 4 faktor yang terjadi di lapangan, faktor-faktor tersebut adalah :

1. Faktor Perencanaan

2. Faktor Perusahaan Kontraktor terkait

3. Faktor Kesiapan Manajemen

4. Faktor Kesadaran Manajemen

\section{Saran}

Dari hasil analisis data, maka disarankan untuk menyempurnakan Sistem Manajemen K3 serta Kelengkapan APD dan fasilitas K3. Sebagai solusi, antara lain dengan cara :

1. Memastikan adanya SDM dalam bidang SMK3 yang memadai sejak masa perencanaan/persiapan proyek

2. Melakukan evaluasi kembali yang sudah dilaksanakan apakah sudah sesuai dengan rencana, serta mengkoordinasikan guna menyempurnakan SMK3

3. Meningkatkan partisipasi konsultan K3 dengan melakukan sosialisasi kepada pekerja guna mengoptimalkan fungsi safety di lapangan

4. Mengevaluasi peralatan Alat Pelindung Diri dan fasilitas K3 yang ada di lapangan, guna memastikan fungsi yang layak dan lengkap 
6. DAFTAR PUSTAKA

[1] Kementerian Ketenagakerjaan. 2018. Kemenaker Klaim Kasus Kecelakaan Kerja Tahun 2017 Menurun,(Online),

(https://nasional.republika.co.id, Diakses 9 September 2018).

[2] Mangkunegara, Anwar Prabu. 2002. Manajemen Sumber Daya Manusia.Bandung: PT. Remaja Rosda Karya.

[3] Peraturan Menteri Tenaga Kerja nomor 5 tahun 1996 tentang Sistem Manajemen Keselamatan dan Kesehatan Kerja. Jakarta: Menteri Tenaga Kerja Republik Indonesia

[4] Peraturan Pemerintah Republik Indonesia nomor 50 tahun 2012 tentang Penerapan Sistem Manajemen Keselamatan dan Kesehatan Kerja. Jakarta: Departemen Pekerjaan Umum

[5] Riduwan. 2003. Dasar - Dasar Statistika. Bandung: Alfabeta.

[6] Suma'mur. 2001. Keselamatan Kerja dan Pencegahan Kecelakaan. Jakarta: CV. Haji Masagung. 